\title{
Smart, Precision or Digital Agriculture and Farming - Current State of Technology
}

\author{
Daniel Honc and Jan Merta \\ Faculty of Electrical Engineering and Informatics, University of Pardubice, Czech Republic \\ daniel.honclupce.cz
}

\begin{abstract}
Together with smart homes, cities and factories, energy hubs and selfdriving cars the smart agriculture or farming could be a way how to increase yields and efficiency as well as improve the welfare of farm animals, grow high quality crops and preserve the natural resources. Smart, precision and digital agriculture and farming current state survey with the technical challenges, interesting applications and future prospects is the aim of the paper. Worldwide and UE view is presented and compared with the situation in the Czech Republic. Authors are seeking for used or at least potential agriculture and farming applications of soft computing methods like fuzzy logic, machine learning and evolutionary computation.
\end{abstract}

Keywords: Smart, Precision, Digital, Agriculture, Farming, Soft Computing.

\section{Introduction}

Climate changes are becoming a real problem and they can cause a decrease in the agriculture production. Growing population increases demand for production while arable landscapes are shrinking due to the urbanization. Fresh water supplies are going to be vital. Farmers compete against each other, trying to reduce costs and differentiate. Weather predictions and monitoring, crop monitoring, insect detection, soil analysis and much more - all connected to IoT network informing the farmers or answering them questions like when should the farmers seed or harvest, what pesticides should they deploy or how to prepare the soil. Use of mobile laboratory or drone for land surveys or crop monitoring is another source of information for their right decisions called as high-tech or precision farming. Through the livestock monitoring ranchers can gather data regarding the health, well-being, and location of their cattle. This can help them to identify sick animals and it lowers the labour costs connected with cattle localization. Monitoring plant and soil conditions is another use case - sensing for soil moisture and nutrients, controlling water usage for optimal plant growth, determining custom fertilizer profiles based on the soil chemistry, determining the optimal time to plant and harvest, reporting the weather conditions.

In the article authors bring survey about smart, precision and digital agriculture and farming current state and perspectives worldwide, find out and describe the situation in the Czech Republic. Authors do not want to concentrate to the economical, ethical, 
societal, political or other conditions or impacts. They are searching for offered or used smart, precision or digital agriculture or farming solutions and look for the potential areas for soft computing techniques as fuzzy logic, machine learning and evolutionary computation. Author do not want to give review of published papers, but they are aiming to the commercial applications. Paper is structured as follows: chapter one is a short introduction, worldwide, EU and Czech Republic view is given in chapter two, technology and typical applications are given in chapter four, interesting solutions are described in chapter five and chapter six gives conclusions.

\section{Worldwide, EU and Czech Republic view}

One of Precision Agriculture (PA) analyses was made by Hexa Report company - Precision Agriculture Market Analysis By Component (Hardware, Software \& Services), By Technology (Variable Rate Technology, Remote sensing, Guidance Systems), By Application, By Region, And Segment Forecasts, 2014 - 2025 [1]. The global precision agriculture market is expected to reach 43.4 billion USD by 2025. American management consulting firm McKinsey \& Company brings different analytics to broad area of the industries. They see efficiency opportunities for emerging economies of PA in the food chain. They define PA or farming in report on How big data will revolutionize the global food chain [2] as a technology-enabled approach to farming management that observes, measures, and analyses the needs of the individual fields and crops. According to them PA development is being shaped by two technological trends: big-data and advanced-analytics capabilities on the one hand, and robotics - aerial imagery, sensors and sophisticated local weather forecasts - on the other.

In the publication Precision agriculture in Europe, Legal, social and ethical considerations - Study [3] authors analyse different ways in which the current EU legislative framework may be affected by the digitisation and automation of the farming activities and the respective technological trends. According to EU publication Precision agriculture and the future of farming in Europe, Scientific foresight study - Study [4] the PA is defined as a modern farming management concept using digital techniques to monitor and optimise agricultural production processes. The following four main future opportunities and concerns regarding PA, or precision farming, in the EU are stated: 1. PA can actively contribute to food security and safety; 2 . PA supports sustainable farming; 3. PA will trigger societal changes along with its uptake; 4. PA requires new skills to be learned. The wide diversity of agriculture throughout the EU, regarding particularly farm size, types of farming, farming practices, output and employment, presents a challenge for European policy-makers. European policy measures therefore should differentiate between Member States, taking into account that the opportunities and concerns vary highly from one country to another. Two annexes are complementary to this study: Annex 1 : Technical Horizon Scan [5] and Annex 2 : exploratory scenarios [6]. The aim of those publications is study, analyse, inform and guide the discussion to identify and explore policy actions in the European Parliament. 
Only two small references to PA can be found in the official publication of Ministry of Agriculture of the Czech Republic in Concept of research, development and Innovation of the Ministry of Agriculture for 2016-2022 [7]. One in the section V. 2. Sustainable production of healthy and quality food and feed of plant origin, paragraph (h) the application of precision agriculture elements in the technological systems of cultivation in order to optimize benefits nutrients in mineral fertilizers and optimizing the dosage, timing and application of pesticides. Second and last PA reference is in the section VI. 3. Technology for livestock production, welfare, systems, ethics and economics of livestock breeding, paragraph (f) innovation and development of technological processes for new types of livestock farming, including aquaculture, the use of automated livestock management systems ('precision livestock farming'), focusing on the level and quality of production; the health and satisfaction of the physiological needs of animals. Czech ministry of agriculture organizes meetings and conferences about PA, allocates and manages European Union subsidy programs. One of them gave arise to a smart and precision agriculture demonstration farm.

\section{$3 \quad$ Terminology and technology}

There are no strong borders and definitions between smart, precision and digital agriculture and farming. At the end it is nothing else than the way how to use hardware and software to give the farmers information needed to make their decisions based on the information rather than on the intuition and help them to control and automate their business. Smart is very popular word and usually we think about acting differently from the normal or standard way with use of the modern technology. In agriculture and farming smart can be anything connected with the sensors, actuators, images from drones, planes, satellites, vehicles, advanced algorithms, weather forecasts with the output to the mobile phones, web servers or clouds. Precision farming is a special part aimed to the precision manipulation with the irrigation, fertilization, pesticides for the crop production and the feeding and pharmaceuticals for the animal production. Practically every variable is processed in digital systems nowadays. The digitalization is standard also for the transmission and the storage. Interconnected systems covering whole farms or even bigger geographical areas can be created. Higher number of information requires different methods for the data processing and visualization (Big Data challenge). The technological changes in the agriculture can be compared to the concept of Industry 4.0. But the processes are different - agriculture is determined by the natural and biological factors. The idea and technology are the same with the same goals - lower costs, higher returns, ecology aspects, product quality, etc. Automotive industry is mostly located in the technologically advanced countries and the application areas are limited within the factory. Agriculture has huge diversity from the cultural, social, geographical or other aspects. Agriculture can be very conservative with high ratio of the labour and being operated on the brink of the economic profitability very frequently. Therefore, consideration and planning of the investments to the new technology is not easy task and the process will be gradual. Successful applications or good practice will help in 
the decision-making of the farmers. Technologies with the potential for smart or precision agriculture or farming are listed below.

Smart farming is an application of Information and Communication Technologies (ICT) solutions such as precision equipment, Internet of Things (IoT), sensors and actuators, geo-positioning systems, Big Data, Unmanned Aerial Vehicles (UAVs, drones), robotics, etc. Radio Frequency Identification (RFID) or Near Field Communication (NFC) is used for the shortest distance communication. Bluetooth or Bluetooth Low Energy (BLE) is used for the objects 10 meters far or closer. For applications sending data over hundreds or even thousands of meters Low Power Wide-Area Network (LPWAN) options are needed - such as Narrowband IoT (NB-IoT), Long Range LoRa, Long Term Evolution (4G) Machine Type Communication (LTE-M) and SigFox. Wide range of sensors are installed in the fields, on smart vehicles and weather stations measuring e.g. humidity, moisture, light, air temperature, $\mathrm{CO}_{2}$. Information from sensors, weather forecast and satellites allow to build models and predictions how the crop will grow, build harvesting strategy, etc.

Instead of applying equal amount of the fertilisers over an entire field, precision agriculture involves measuring the within-field soil variations and adapting the fertiliser strategy accordingly. This leads to the optimised fertiliser usage, saving costs and reducing the environmental impact.

Smart sprinklers activate the automated irrigation, connected coolers and heaters in the storage and transportation facilities enable sustainable conditions for the product and help reduce the waste. Intelligent LED lighting automatically adjusts to the changing conditions and ensures every part of the greenhouse or storage space gets the right amount of light.

IoT-driven smart greenhouses can intelligently monitor as well as control the climate, eliminating the need for the manual intervention. They become a self-regulating, micro-climate-controlled environment for the optimal plant growth.

In most cases, drones work as an IoT-based monitoring system in the smart agriculture, as the tools for the farm mapping and on-demand irrigation and pesticide treatment.

Sensors have been developed for the various parts of the cattle, including the neck, hooves, stomach and tail in an effort to reduce the mortality rate associate with birth, prevent cattle rustling and illness, monitor the dietary health, and monitoring the amount of the nitrogen in a cow's urine. Additionally, the implementation of IoT combined with Artificial Intelligence (AI) can help improve breeding and identify which breeds are "top producers" in order to increase both the quality and the volume of the milk.

Large farm owners can use wireless IoT applications to monitor the location, wellbeing and health of their cattle. With this information, they can identify sick animals, so that they can be separated from the herd to prevent the spread of disease. Farm owners are keep tabs on their herd through GPS sensors. These devices allow farm owners to track their cattle over long distances, even in remote areas. Using different scenarios/options they can provide this information in different ways:

- Geo-fencing - when the device leaves a pre-defined area 
- Chrono-fencing - the device sends a status update after staying at a location for a certain pre-defined time

- On-demand location request - request to device to update its status and position.

Vehicles are equipped with the precise GPS and machine learning algorithms to enable self-driving, sensors, computer vision for precision farming capabilities.

Categories of vehicles control level are:

- Guidance - operator is needed - maintain row-to-row vehicle accuracy in the field in order to reduce overlaps and skips

- Coordination \& Optimization - vehicle and environmental data are used to develop an information hub for operator

- Operator Assisted Autonomy - operator is monitoring automated functions and only providing backup and support when needed

- Supervised Autonomy - in-field supervision is needed while unmanned vehicles perform designated tasks

- Full Autonomy - remote supervision - such as from the farm office - or via AI.

Companies like GEOSYS, planet or ASTRO DIGITAL deliver daily imagery from the satellites for precision agriculture purposes. For example Sentinel satellites from ESA allow the creation of maps of the spatial variability of many measurements and variables - crop yield, terrain features/topography, organic matter content, moisture levels, nitrogen levels etc.

\section{Soft computing techniques application areas}

Areas for use of the soft computing techniques as fuzzy logic, machine learning and evolutionary computation are practically unlimited for the smart, digital or precision agriculture or farming. Fuzzy logic and neural networks help to create models of the farmers' behaviour and expert knowledge to build the decision and analytical systems, to predict the future trends, consider case studies or carry out on-line optimisations. Evolutionary algorithms can be used for the optimisation of operational, investment or logistic decisions and operations. Data, methods and hardware for the artificial intelligence are available and can be applied for the image processing or other tasks connected with the agriculture and farming.

\section{Commercial PA and smart agriculture solutions}

PA solution are stated so the reader can get the ideas and information about the application possibilities of the new technologies in the agriculture and farming especially connected with the soft computing techniques. 
CropX [8] - CropX app can help figure out exactly how much to irrigate the field, by providing an irrigation prescription that is constantly adapting to the changing conditions of the field. By analysing crop growth against crop models, prediction the crop's needs and expected growth, detect any deviation and identify early-stage field variability and non-uniformity of the crop growth. Integration of crop models, satellite imagery and weather forecast data alongside the soil data creation map nutrient distribution across the field and zone-specific nitrogen application recommendations.

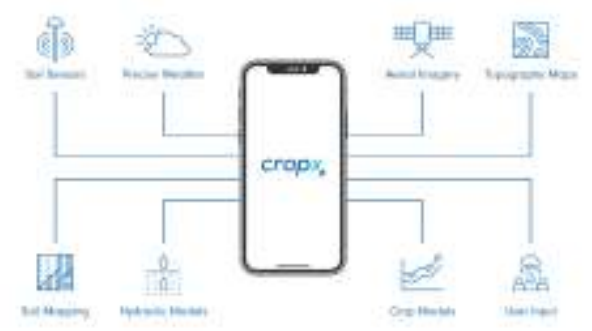

Fig. 1. CropX platform [8]

Arable [9] - Arable Mark 2 is all-in-one weather and crop monitor - precipitation, evapotranspiration, radiation, plant health, weather, harvest / event timing with cellular connectivity.

Gamaya [10] - patented ultracompact hyperspectral imaging camera with machine learning engine for precision farming and global crop intelligence based on agronomic insights.

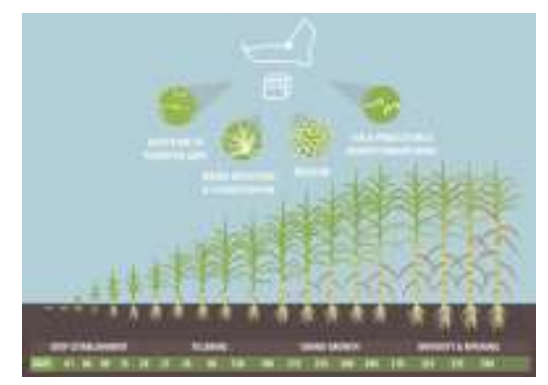

Fig. 2. Canefit - smart solution for sugarcane cultivation [10]

Ceres Imaging [11] - irrigation management, nutrient management, pest and disease management, labour management with high-resolution multispectral imagery of chlorophyll, colour infrared, NDVI, thermal and water stress.

Mothive [12] - devices installed next to the plants collect environmental and soil data. Bespoke Machine Learning models predict crop growth conditions, diseases and crop harvest. Recommendations and alerts delivered via dashboard, SMS, email. Live $\&$ historical data, intelligent automation (irrigation \& ventilation) and specific tasks delivered to robots in the future. 


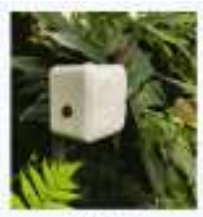

Monitor

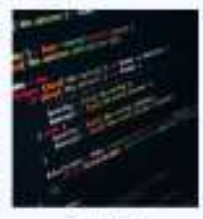

Prodict

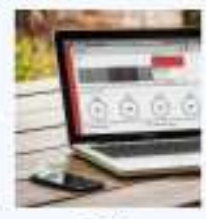

Troek

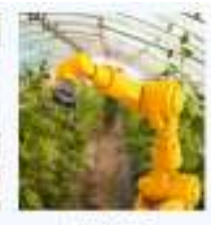

Automato

Fig. 3. Mothive Ladybird [12]

PrecisionHawk [13] - autonomous UAV that collects high-quality data through a series of sensors that are used for the surveying, mapping, and imaging of agricultural land. Equipped with sensors - lidar, thermal, multispectral, hyperspectral.

AgEagle [14] - aerial imagery-based data collection and analytics solutions - "tractor tough," precision drones capable of capturing thousands of ultra-high resolution images and producing actionable intelligence.

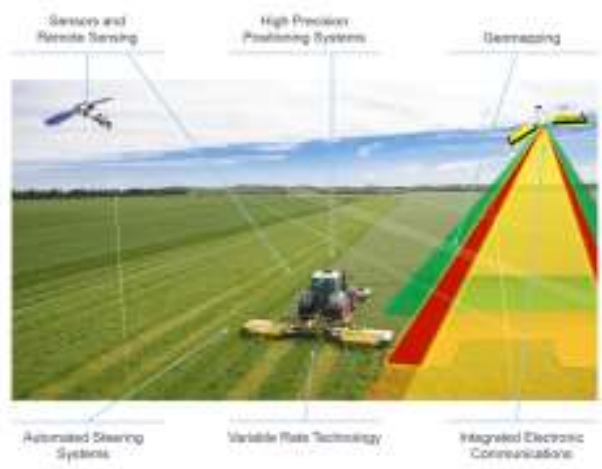

Fig. 4. AgEagle - precision farming [14]

Phytech [15] - plant-based application for the optimized irritation for corn, almonds, citrus, cotton and apple and other crops.

WaterBit [16] - automated irrigation solution - one field, many microblocks, remote irritation control, planning and scheduling.

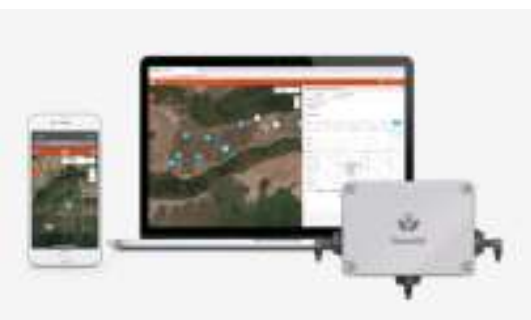

Fig. 5. WaterBit - precision farming [16] 
Aker Technologies Inc. [17] - accurate crop monitoring of disease, insects, and other stresses. AkerScout - crop scouting to help document and prioritize in-season crop damage, imagery and analytics.

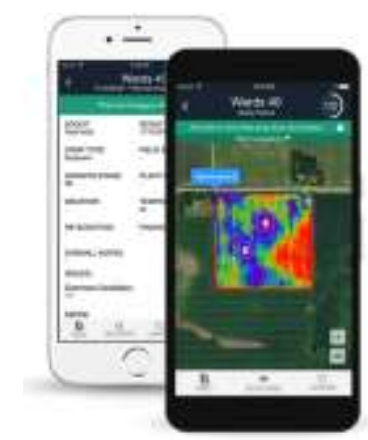

Fig. 6. AkerScout - crop scouting tool [17]

JMB North America [18] - cow-monitoring solutions for American beef and dairy producers - calving detection, heat detection, nutritional monitoring, health monitoring.

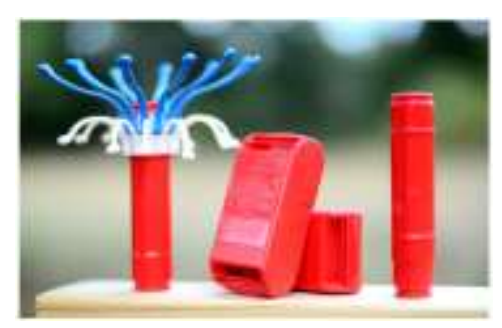

Fig. 7. JMB North America [18]

Case IH [19] - producer of agriculture machinery with advanced farming systems, displays, autoguidance, section \& rate control.

AgroCares [20] - Lab-in-the-box - direct on-site access to testing services, Scanner - instant, on-the-spot monitoring of nutrients in soil, feed and leaf, Scoutbox - digitally determination, counting and location of harmful insects.

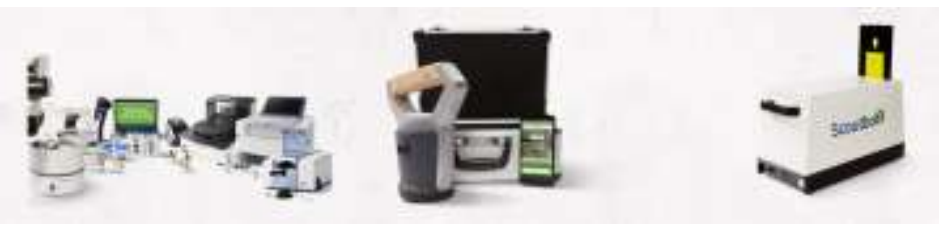

Fig. 8. AgroCares - Lab-in-the-box, Scanner, Scoutbox [20] 
CleverFarm [21] - Czech company dealing with PA, online records of agronomic activities, sensors, satellite imagery and land registry.

Digital Garden Lab [22] - open-source community exploring new forms of digital augmentation to facilitate urban community gardening and urban landscapes.

\section{Conclusions}

Digitalization trends and smart technologies are everywhere around us. Agriculture or farming belongs historically to one of the most rigid human activities. Together with the climate changes, population grow, water resources decrease the smart or precise technologies give chance to cope with the coming challenges with respect to the production quality, operate environmentally friendly and humanely to the animals. Another factor is also to help the farmers to do informed decisions even without extensive experience or education. Images from the satellites, planes or drones in broader frequency range than only within visible light bring new source of the information. Similarly sensors on the fields or carrying on the animals have not been used in the past. Accurate and localized weather forecast are also improved much in the recent years. But the information alone is not enough. Data analysis techniques, models, optimization methods are theoretically known and waiting for their application. The potential of the soft computing methods is indisputable. Image and other data analysis are made by the machine learning techniques. Fuzzy logic and neural networks build the models and experts systems used for the analysis, optimization and predictions. Evolutionary algorithms are used for the optimization in economical, logistical and technological areas. Big Data algorithms process information from huge amounts of sensors, imagery and weather forecast. The data and results are stored in cloud services, displayed on the mobile phones or tablets and sent to the workers, machinery, robots, drones and planes to close the feedback actuate and control. Security of the system must be also a priority for the future. State or funding support for the introduction of the new technologies will be needed together with the new legislation. The solution must be in balance between traditional approaches and possibilities of the new technologies. For example, is it worth to use advance technology and do not carry out deep plowing because of the fuel savings and let the water and fertilizer run off the fields? The new technology will work if we see the bigger picture and all activities play together.

\section{Acknowledgment}

This research was supported by SGS grant at Faculty of Electrical Engineering and Informatics, University of Pardubice. 


\section{References}

1. Hexareports, Precision Agriculture Market Analysis By Component, http://www.hexareports.com/report/precision-agriculture-market, last accessed 2020/4/18.

2. McKinsey, How big data will revolutionize the global food chain, https://www.mckinsey.com/business-functions/mckinsey-digital/our-insights/how-big-data-will-revolutionizethe-global-food-chain, last accessed 2020/4/18.

3. Publication office of the EU, Precision agriculture in Europe, https://op.europa.eu/en/publication-detail/-/publication/1d338444-1783-11e8-9253-01aa75ed71a1/language-en/format-PDF/source-search, last accessed 2020/2/1.

4. Publication office of the EU, Precision agriculture and the future of farming in Europe, https://op.europa.eu/en/publication-detail/-/publication/40fe549e-cb49-11e7-a5d501 aa75ed71a1/language-en, last accessed 2020/2/1.

5. Publication office of the EU, Precision agriculture and the future of farming in Europe, https://op.europa.eu/en/publication-detail/-/publication/6a75e0ac-90ae-11e9-936901 aa75ed71a1/language-en/format-PDF/source-search, last accessed 2020/2/1.

6. Publication office of the EU, Precision agriculture and the future of farming in Europe, https://op.europa.eu/en/publication-detail/-/publication/77b851b0-90b1-11e9-936901 aa75ed71a1/language-en/format-PDF/source-search, last accessed 2020/2/1.

7. eAGRI, Koncepce výzkumu, vývoje a inovací Ministerstva zemědělství na léta 2016-2022, http://eagri.cz/public/web/file/461417/Koncepce_vyzkumu_vyvoje_a_inovaci_Ministerstva_zemedelstvi_na_leta_2016_2022.pdf, last accessed 2020/2/1.

8. CropX, https://www.cropx.com/, last accessed 2020/2/1.

9. Arable, http://www.arable.com/, last accessed 2020/2/1.

10. Gamaya, https://gamaya.com/, last accessed 2020/2/1.

11. Ceres Imaging, https://www.ceresimaging.net/, last accessed 2020/2/1

12. Mothive, https://www.mothive.com/, last accessed 2020/2/1.

13. PrecisionHawk, agriculture, https://www.precisionhawk.com/agriculture, last accessed 2020/2/1.

14. AgEagle, https://www.ageagle.com/, last accessed 2020/2/1.

15. Phytech, https://www.phytech.com/, last accessed 2020/2/1.

16. WaterBit, https://www.waterbit.com/, last accessed 2020/2/1.

17. Aker, https://aker.ag/, last accessed 2020/2/1

18. JMB North America, technology, http://cowmonitor.com/technology/, last accessed 2020/2/1.

19. Case IH, Advanced Farming Systems, https://www.caseih.com/northamerica/en-us/innovations/advanced-farming-systems, last accessed 2020/2/1.

20. AgroCares, https://www.agrocares.com/en, last accessed 2020/2/1.

21. CleverFarm, https://www.cleverfarm.org/, last accessed 2020/2/1.

22. Digital Garden Lab, https://digitalgardenlab.cz/, last accessed 2020/4/18. 